\title{
VALORISATION OF HISTORY AND \\ LANDSCAPE FOR PROMOTING THE MEMORY OF WWI
}

\author{
E. Nocerino ${ }^{\text {a }}$, F. Menna ${ }^{\text {a }}$, I. Toschi ${ }^{\text {a }}$, D. Morabito ${ }^{\text {a }}$, F. Remondino ${ }^{\text {a }}$, P. \\ Rodríguez-Gonzálvez ${ }^{\mathrm{b}, \mathrm{c}}$ \\ a 3D Optical Metrology (3DOM) unit, Bruno Kessler Foundation (FBK) \\ Via Sommarive 18, 38121 Trento, Italy \\ E-mail: $<$ nocerino $><$ menna $><$ toschi $><$ morabito $><$ remondino $>@$ fbk.eu \\ Web: http://3dom.fbk.eu \\ ${ }^{\mathrm{b}}$ TIDOP Research Group, Higher Polytechnic School of Avila, University of \\ Salamanca, Hornos Caleros, 50, 05003 Ávila, Spain \\ ${ }^{c}$ Department of Mining Technology, Topography and Structures, University of \\ León, Avda. Astorga, s/n, 24401 Ponferrada, León, Spain \\ E-mail: <p.rodriguez>@unileon.es
}

\begin{abstract}
In recent years many activities were conducted to commemorate the 100th Anniversary of the First World War (WWI) outbreak. Among these, the VAST (valorisation of history and landscape) project (http://vast.fbk.eu) was part of the initiatives promoted by the Autonomous Province of Trento (Italy) as a tribute to WWI events in the region. The project was primarily aimed to document and promote, through $3 \mathrm{D}$ digitization approaches, ICT technologies and communication material, the memory of sites, theatre of the world conflict. The Trento's area was under the Austro-Hungarian Empire until the end of WWI and on the border with the Italian Kingdom. The area represented a crucial and bloody war front between the Austrian and Italian territories. It was thus constellated of military fortresses, trenches and tunnels, most of them now ruined and at risk to slowly disappear. 3D surveying and modelling techniques were exploited to produce 3D digital models of structures and objects, along with virtual tours, dissemination material and a
\end{abstract}


WebGIS of the area. All the products are now used for restoration, valorisation, educational and communication purposes.

Keywords: 3D surveying; 3D modelling; First World War; War heritage; Surveying; WebGIS; Education; Awareness-Raising.

\section{Introduction and research aims}

VAST (valorizzazione storia e territorio / valorisation of history and landscape) was an interdisciplinary project with the ambition of exploiting state-of-the-art 3D modelling and visualization technologies to reinforce and enrich with new significance heritage sites and monuments on the mountainous area in the North East of Italy related to the First War World (WWI). The area was part of the AustroHungarian Empire until the end of the WWI and represented one of the crucial border with the Italian Kingdom (Fig, 1a). Consequently, the territory was constellated of military fortresses (Fig. 1b), trenches and underground tunnels that represent a unique heritage patrimony, especially for the plateau of Luserna, Lavarone and Folgaria (Trento's province). This area is lived by an ethnic and linguistic minority (the Cimbrians) descending from Germans and speaking Cimbrian, a Bavarian dialect that has maintained characteristics of Middle High German [1]. The VAST project was strongly supported by members of the Cimbrian community, persuaded that new ICT technologies would have helped in the valorisation and preservation of their cultural heritage.

Most of the military WWI constructions are now ruined and risk to slowly disappear (Fig. 1c). Therefore, the primary goal of the VAST project was to enhance the conscience of what the war had represented for the local community, in 
particular for the young generations that do not have directly witnessed its cruelty. Military structures and artefacts were surveyed and modelled in 3D to produce new dissemination and communication materials (3D digital models, scientific and communicative articles, virtual tours, conferences, WebGIS platforms, etc.) now used both in museums and along the main routes running across the territory. The realized products comprise classic informative resources, mainly devoted for an adult audience, as well as virtual and interactive reconstructions of war buildings, objects and landscape, more appropriate for the young generations.

The project was run in collaboration with various partners and local stakeholders, with complementary expertise in cultural and technical research field. This allowed to reach the goal of digitizing and communicating WWI heritage and memory for the commemoration of the 100th Anniversary of the war outbreak.

The aim of the article is to showcase how ICT solutions, 3D surveying and modelling procedures could facilitate and improve the dissemination of heritage information, enhancing valorization and attracting young generations to heritage places.

a)

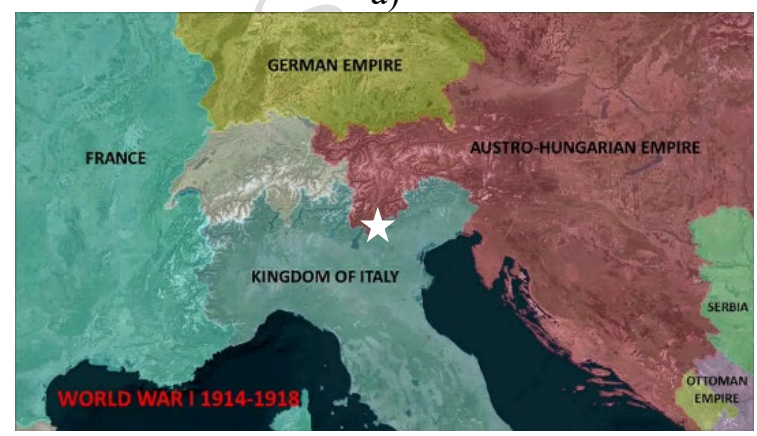

c)

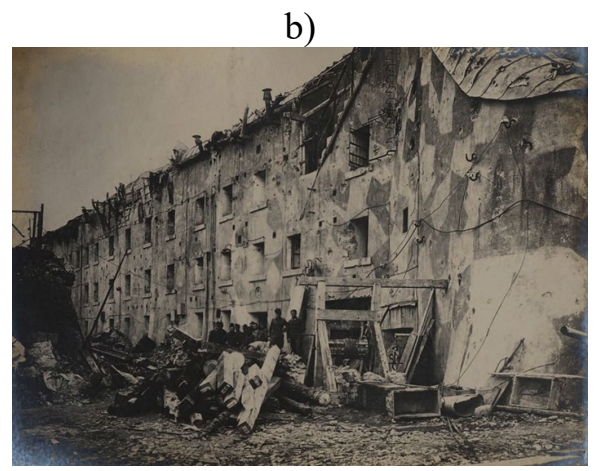

d) 

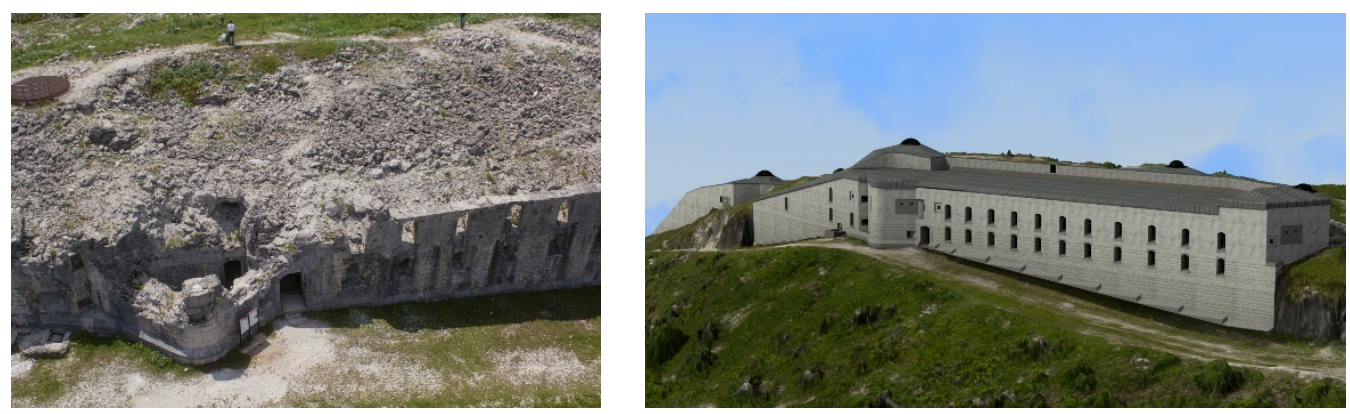

Fig. 1. (a) Borders of contending countries during WWI. The white star indicates the location of the area interested by the VAST project. (b) An historical picture of Luserna fort. (c) Cherle fort or werk Sebastiano as it appears today and (d) its virtual reconstruction.

\subsection{The Austro-Hungarian forts in the Trentino area}

In the XIX century, the Trentino-Alto Adige region was the last Italian territory still belonging to the Austro-Hungarian Empire. Aiming at protecting it against the spread of the Italian unification movements, more than 50 military fortifications (werk in German) were built in the southern-east part of the region. In particular, a double set of fortifications organised in an internal and external ring were erected to protect the city of Trento, capital of the Trentino province [2]. From the 1830s to the WWI outbreak, four generations of forts, corresponding to six different construction phases, were designed and built, each of them at different heights on the mountains:

- the 1st generation (first three phases) comprises forts situated at the entrance of the valleys, as a natural bottlenecks and block of the main routes;

- the 2nd generation (beginning of 1880) features fortifications at higher altitude, characterized by a simple planning scheme known as 'Trentino style';

- the 3rd generation, called 'Vogl era', was built to complete the defence belt of the eastern Trentino front, and consist of armoured forts, fitted with reinforced domes and shields for the artillery in the casemate; 
- the 4th generation (1904-1914) was promoted by the Austro-Hungarian general Conrad von Hötzendorf and is characterised by fortresses made in concrete and steel located on the plateau and on the top of mountains.

The military fortresses considered in the VAST project and hereafter presented belong to the 4th generation. Each fortification, with casemate, rotating domes, corridors, underground passageways and reinforced blocks, was often realized with the main body completely carved into the rock in order to be camouflaged, so that only the façade was partly visible from outside.

\subsection{State of the art in heritage documentation with multi-data sources}

In the last years, digital 3D modelling and visualization techniques have been widely employed to document sites of cultural significance, as well as patrimony threatened by both human (war, mass tourism, pollution) and natural (flooding, sea water rising, earthquakes) influences. Digital reconstruction implies the representation of the artefact or monument to its original state [3] and requires the verification of the suggested reconstruction through additional information, such as historical documents, images, records, etc.

In Kinji et al. [4], for example, the approach to 3D modelling of buildings of the Citadel of Bam, a UNESCO world heritage site destroyed after an earthquake, is discussed. Complementary data, such as 2D maps, photos, maps, are used to provide a digital restoration of the site. Examples of multi-data source and multisensor approaches are discussed in Guidi et al. [5], Remondino et al. [6] and TorresMartínez et al. [7]. Guidi et al. [8], Hanke et al. [9] and Rodríguez-Gonzálvez et al [10] integrated 3D data with historical sources. Digital restoration of lost cultural heritage using photogrammetry and crowdsourced images is the aim of the Rekrei project (https://projectmosul.org, [11]). 


\subsection{WWI commemoration projects}

All around the World, the centenary commemoration of WWI (also called Great War) outbreak has been recognised as key moment, not only to honour who sacrificed their lives in the war, but also to understand the influences of those events on our society, and convey their memories to young generations.

Besides a number of national and local events, ceremonies, and exhibitions, also international organizations have promoted several initiatives. For example, Europeana, the European digital platform for cultural heritage, has sponsored three digital projects:

- the 'Europeana Collections 1914-1918' (http://www.europeanacollections-1914-1918.eu): it is a digital collection of material from national libraries of several countries that were on different sides of the historic conflict.

- the 'Europeana 1914-1918' (http://www.europeana1914-1918.eu): it is a digital archive of stories, objects, and historical material about the First World War collected and digitized across Europe

- 'EFG1418' (http://project.efg1914.eu): the European Film Gateway is a collection of films and related documents from and related to WWI.

The 'World War I Centenary: Continuations and Beginnings', funded by the JISC WW1 Open Educational Resources (OER) Programme (http://wwlcentenary.oucs.ox.ac.uk), was a collaboration involving both academic and non-academic experts in different disciplines with the aim of collecting and sharing multi-media contents, and providing it through thematic collections that could be used for innovative teaching approaches and studies, verification of hypothesis and theories, revision of the War itself in its social, cultural, historical 
and political context. Digital techniques were also employed to virtually simulate the underground warfare using Unity 3D [12]. Another project designed to share online cultural heritage collection related to the Great War is the 'World War I Memorial Inventory Project' (http://ww1 mproject.org). The website is a searchable database of U.S. WWI memorials, that includes images, history, state of conservation, the names of veterans. 3D models, created employing photogrammetry, are also available in a 3D web viewer based on Sketchfab (https://sketchfab.com).

As further proof that WWI represents a milestone in the history of Trentino, it is worth mentioning the 'World War I 1914-1918. Trentino, Italy, Europe' project (http://isig.fbk.eu/projects/world-war-i-1914-1918-trentino-italy-europe). Its main aim was to deepen cultural and social history of the war at different scales, from the Trentino territory up to the broader European context.

\section{Project's methodology and results}

\section{$2.13 D$ surveying and modelling of war scenarios and artefacts}

Great efforts have been devoted in the modelling of the considered AustrianHungarian forts. Indeed, the majority of the WWI forts in the Trentino region are nowadays ruined, for the damages naturally induced by the war hostilities and for the Fascism law enforcing the removal of all iron pieces from military buildings. The most effective and less expensive way to show how WWI forts should have appeared at the outbreak of the war is through the adoption of $3 \mathrm{D}$ digital representation techniques. The integrated methodology for the digital reconstruction of such military architectures consists of:

- Digitization of historic drawings as base for the modelling workflow; 
- Field surveying (aerial and terrestrial photogrammetry, laser scanning, panoramic photography) to record the actual condition of the forts;

- Derivation of missing information (construction materials, shape of coverage, etc.) from additional material (historical photos and books);

- Integration of the produced 3D model into the digital surface model for visualization purposes.

\subsubsection{Study and digitization of historic documents}

A scrupulous literature review was carried out in order to identify the original construction drawings of the Austro-Hungarians fortifications (Fig. 2a). The drawings were digitized using close-range photogrammetric surveys in order to produce high-resolution orthoimages of the drawings [13]. Several images were acquired with a calibrated digital single lens reflex (DSLR) camera and processed following a standard fully automated photogrammetric processing pipeline, from the image orientation step (Fig. 2b) to the dense image matching phase, mesh generation and orthophoto production. The obtained orthoimages (Fig. 2d) were then used as basis for the 3D modelling procedure (Section 3.1.3). The accuracy of the proposed methodology for orthophoto production was assessed through comparisons with traditional rectification methods, both analytical and geometrical (Fig. 3 and Table 1). Control points and reference measurements were derived from reference grid based on the actual measurements shown in the paper drawing. Both number and position of reference points and measurements were selected in order to minimize and uniformly distribute residuals over the whole rectified image. The distances between the reference grid (Fig. 3) and the corresponding points taken on the rectified images are reported in $\mathrm{mm}$ at the given map scale $(1: 100)$. Table 1 summarizes the differences for 13 points uniformly distributed on a rectified 
historical drawing. The results showed that the adopted photogrammetric-based approach was generally comparable with the classical procedure, with the advantage of being fully automated and independent from the operator precision. However, when the historical drawings displayed big deformation, all rectification methods produced differences greater than the plotting accuracy.

Other historic sources of information were also collected and digitized: antique topographic maps, war front position during the years of conflict, localization of cableways position and trenches. All these digitised documents were stored in the project's WebGIS application (Section 3.3).

a)

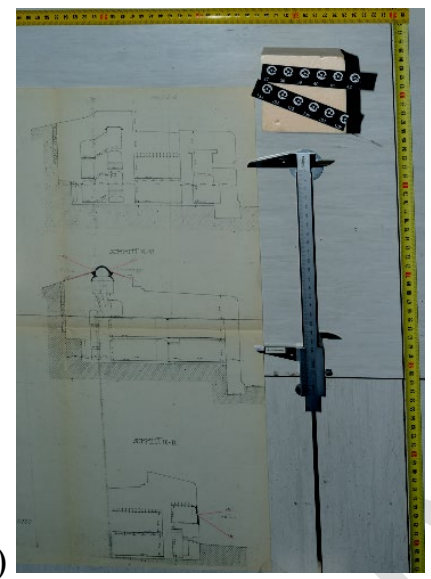

b)

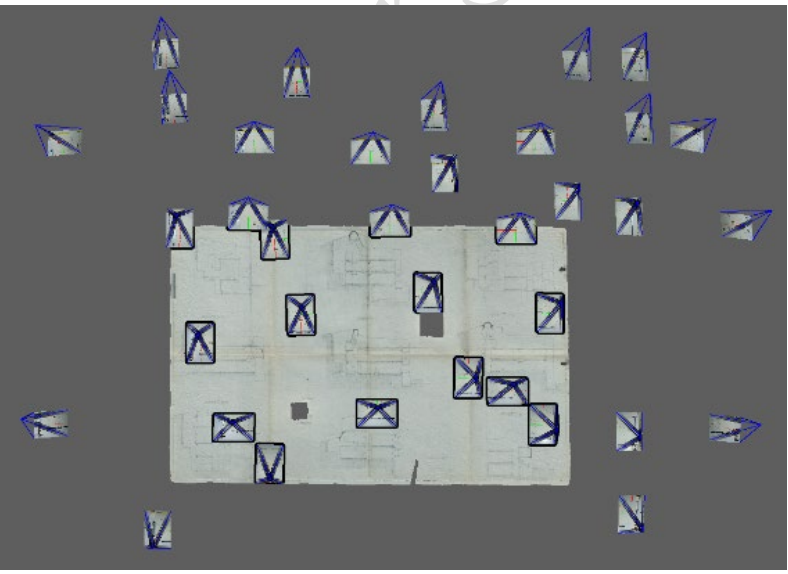

c)

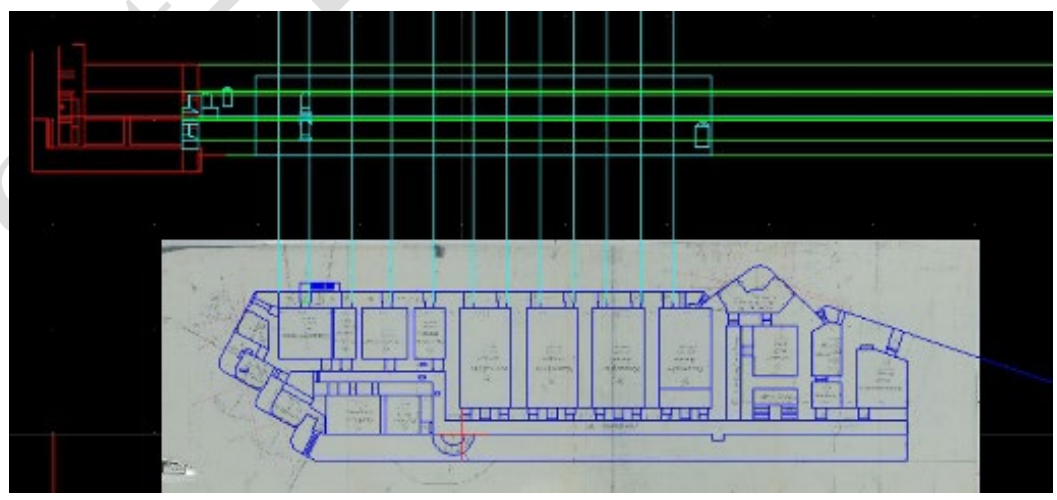

Fig. 2. (a) Example of 2D design drawing. (b) Photogrammetric network for the 2D drawing ortho-rectification procedure. (c) Extraction of drawing elements.

Rectification
method: Analytic
(polynomial with
18 points)
Rectification method: Analytic (affine with 18 points)

\section{Rectification method: Geometric (16 lines)}

Orthoimage from the photogrammetric survey 

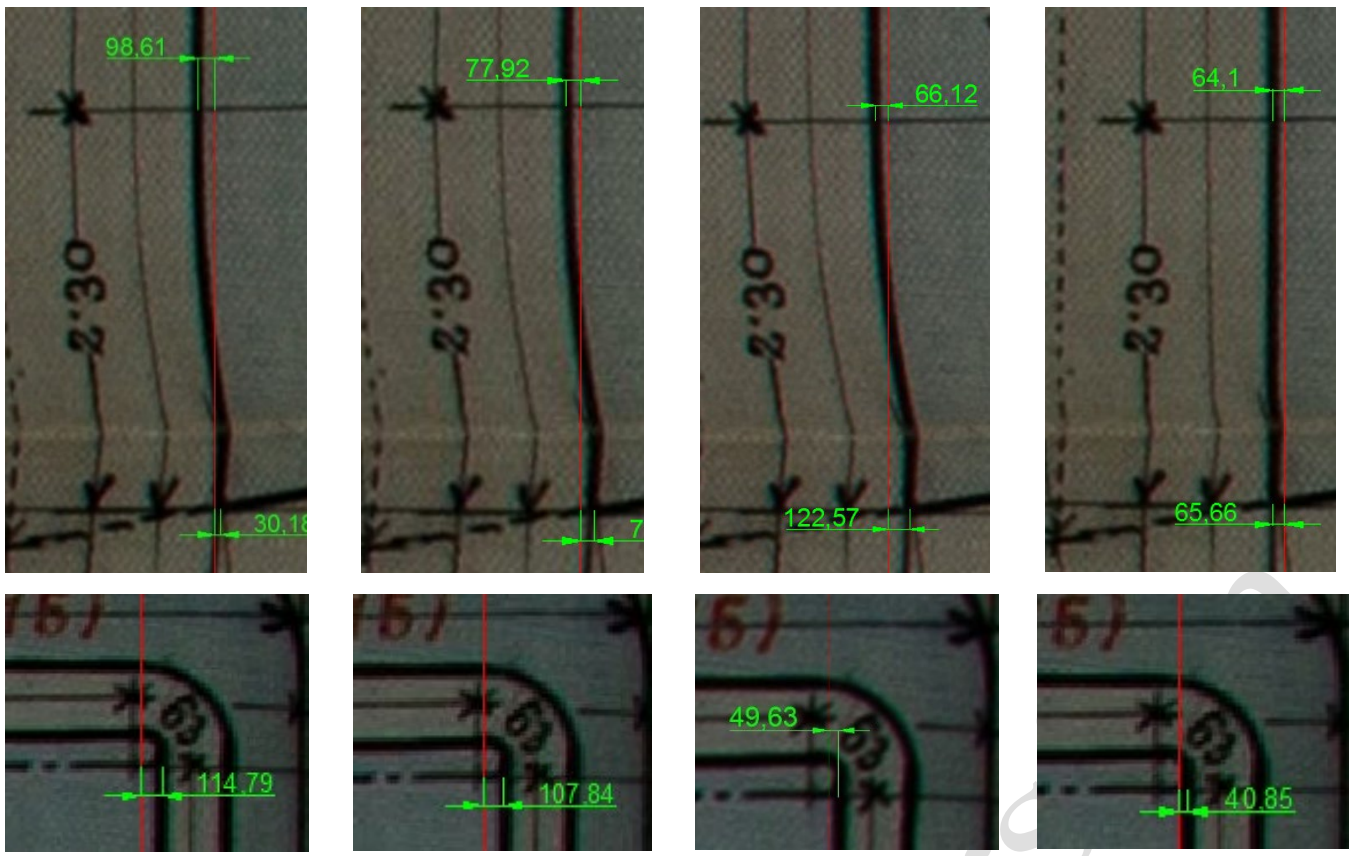

Fig. 3: Comparisons between four different rectification methods.

Table 1. Mean and maximum differences (in mm @ map scale) between reference grid and corresponding points taken on the rectified images.

\section{Rectification method}

Polynomial

Affine

Geometric

Orthoimage

\section{Mean difference [mm@1:100]}

55.45

100.03

63.93

53.88

$\begin{gathered}\text { Max difference } \\ \text { [mm@1:100] }\end{gathered}$
185.54
387.06
122.57
119.32

\subsubsection{Data acquisition on site}

Terrestrial and drone/UAV (Fig. 4a) photogrammetric surveys, integrated with terrestrial laser scanning acquisitions (Fig. 4b), were conducted to digitally record and then measure the actual situation of the considered forts. Indeed, dimensions and details of construction drawings were often imprecise due to on site final modification and military tactics. Therefore, photogrammetric and laser scanning surveys were realized mainly to: (i) obtain reference measurements (for example, height and length of the façades, number and position of the windows), (ii) select the design project plans truly used to build the forts, (iii) verify the correctness of historical designs used in the later stages of modelling, (iv) integrate the missing 
design data and (v) geo-locate the fortifications. The surveying operations were usually concentrated on external and visible part of the structures as most of the interior/indoor parts are in danger and accesses are normally forbidden. For some forts the underground passages were surveyed to document and visualize hidden structures [14].

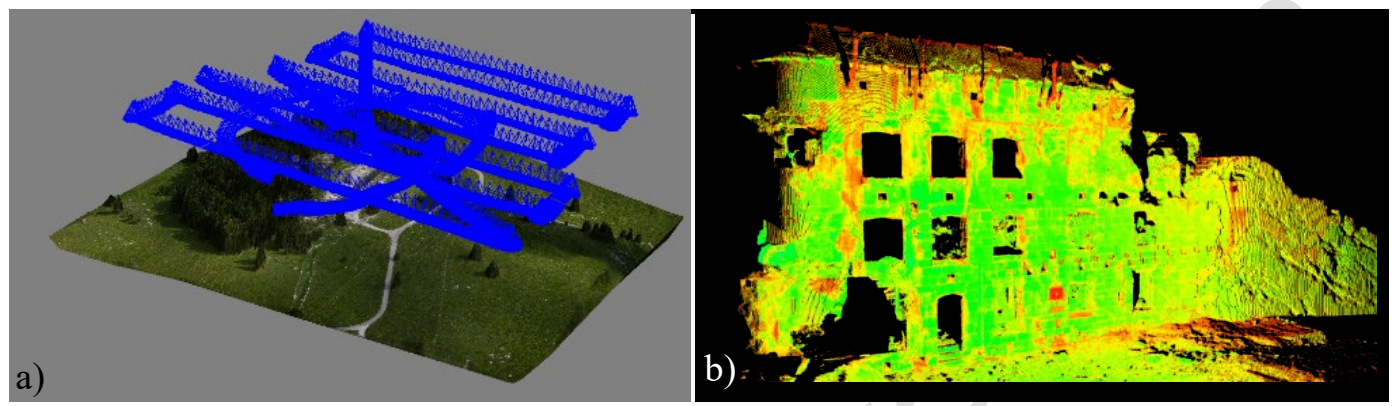

Fig. 4. (a) UAV photogrammetric survey network on the Verle fort. (b) Laser scanner data (Leica HDS7000) of Vezzena fort.

Starting from a dense point cloud of underground structures acquired with terrestrial laser scanning - TLS (Fig. 5a), a simplification approach aimed at developing a traceable procedure of the whole process to avoid subjective interpretation in the modelling process [13]. The method, based on free software applications, involved a two-step procedure: (i) a high spatial resolution mesh generated with Poisson algorithm [15] from the input point cloud and (ii) a successive iterative geometric optimization based on the quadratic edge collapse algorithm [16]. This iterative procedure helped to understand the level of simplification we could apply in order to respect scale representation constraints.

Following the described procedure an $87 \%$ reduction of the triangles, preserving significant geometric information, was obtained for the $110 \mathrm{~m}$ long underground tunnel, part of the Luserna military fortification (Fig. 5b). 
a)

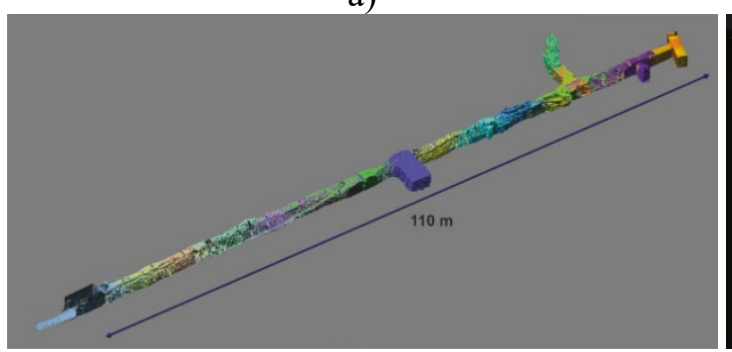

b)



Fig. 5. The aligned 3D TLS data (a) and final texturized model (b) of the underground tunnel

\subsubsection{D models of forts}

The original construction drawings (Section 3.1.1) were used as basis for the 3D modelling procedure. Classic CAAD (computer aided architectural design) modelling tools (e.g. extrusion, Boolean operations of solids) were applied to produce digital models of the forts. Geometrical information extracted from longitudinal and cross sections, elevations, were employed to extrude the original height and position of the different floors. Similarly, 3D solids of domes and roofs were created from 2D polylines and curves, derived from the available design drawings. 3D models representing the geometry of the buildings were then enriched with a texture mapping process: virtual textures were created on the basis of information from existing forts of the same period that have been already restored, and historical images (Fig. 6).
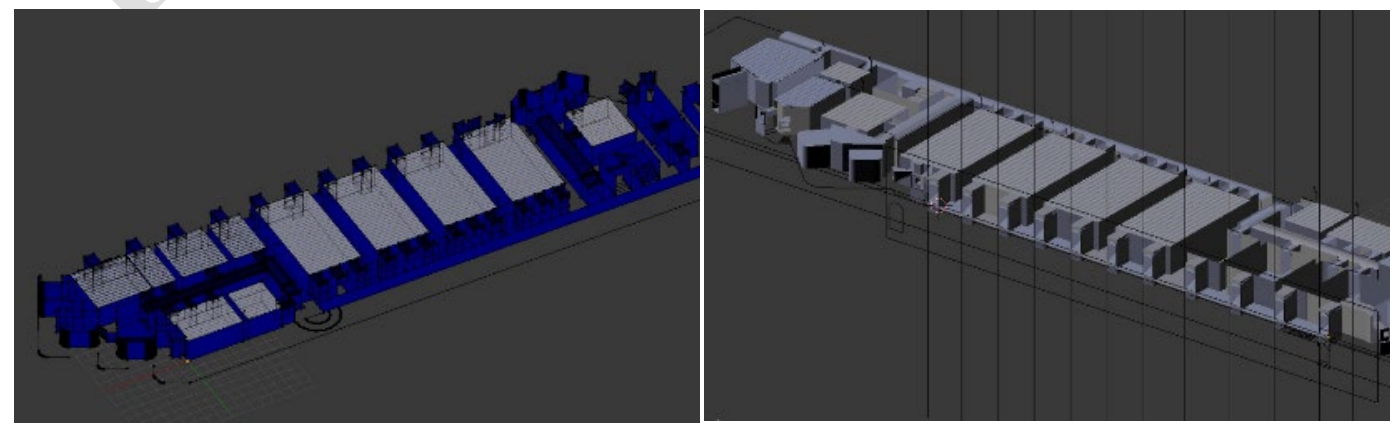

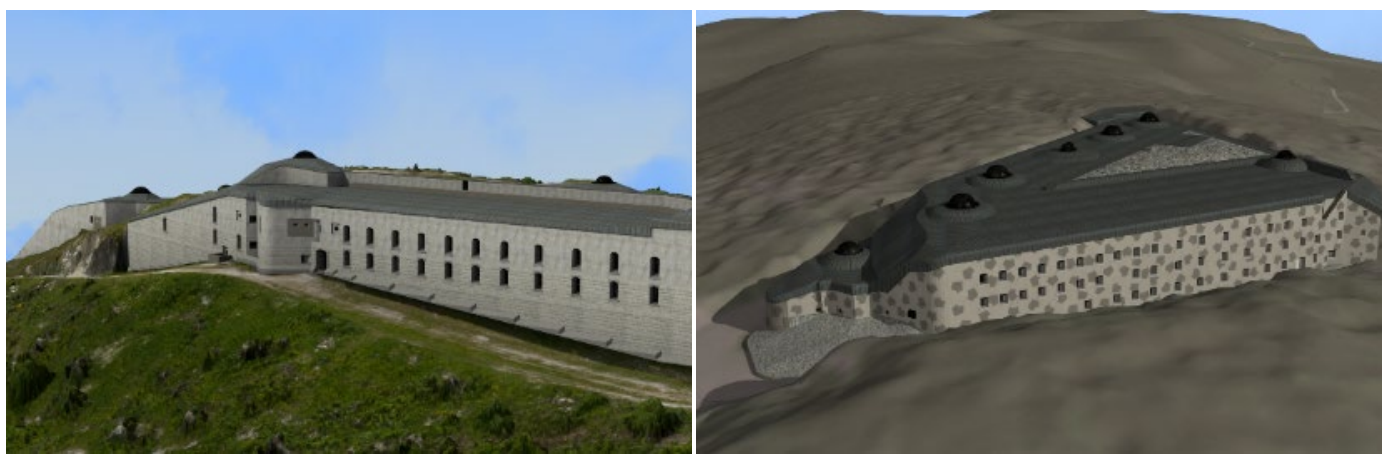

Fig. 6. Steps of CAAD modelling of forts and two results of the produced 3D models inserted into their digital environment.

Based on the realised 3D models, new totems as communication tools placed close to the forts (Fig. 7.) For each fortification, a video accessible from the web pages or on the youtube channel of FBK-3DOM (https://www.youtube.com/user/3DOMFBK/videos) was finally created.

a)

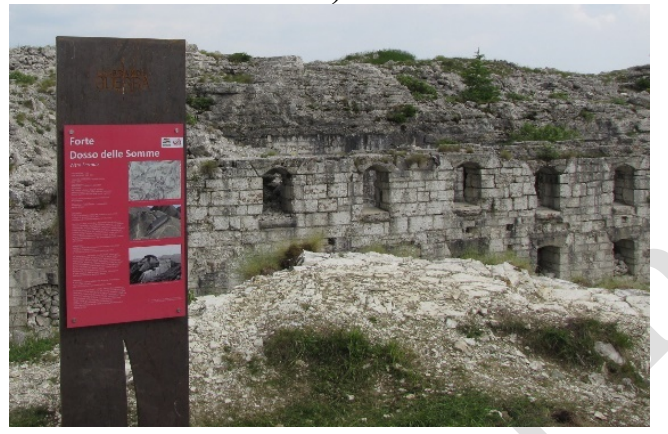

b)

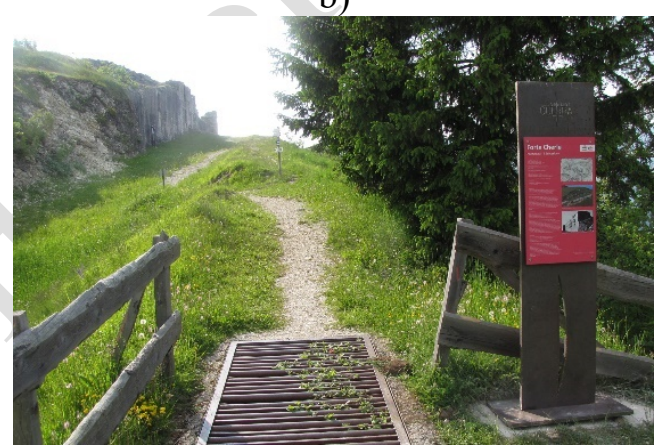

Fig. 7. Totem or communication panels.

\subsubsection{D models of war artefacts}

On the Trentino WWI plateaus several items used by the Austrian and Italian troops were found. These artefacts, now preserved and displayed in a museum, were digitized with a combined surveying approach: (i) A 3D fringe projection scanning was employed to record the geometry of the assets (Fig 8a); (ii) high resolution images were acquired, processed through a photogrammetric workflow and coregistered to the mesh model obtained with the fringe projection scanner. The RGB colour information from the images were then mapped to the geometry to produce high resolution textured mesh models (Fig. 8b). 
a)

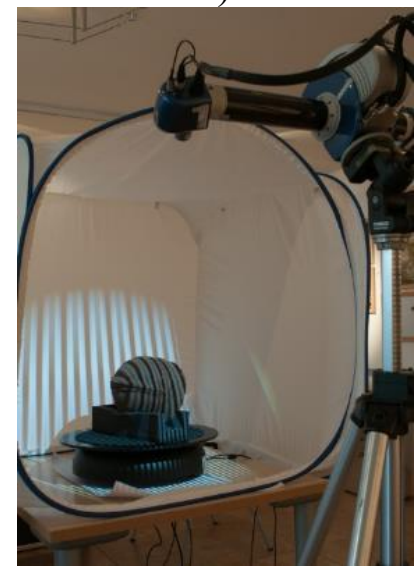

b)

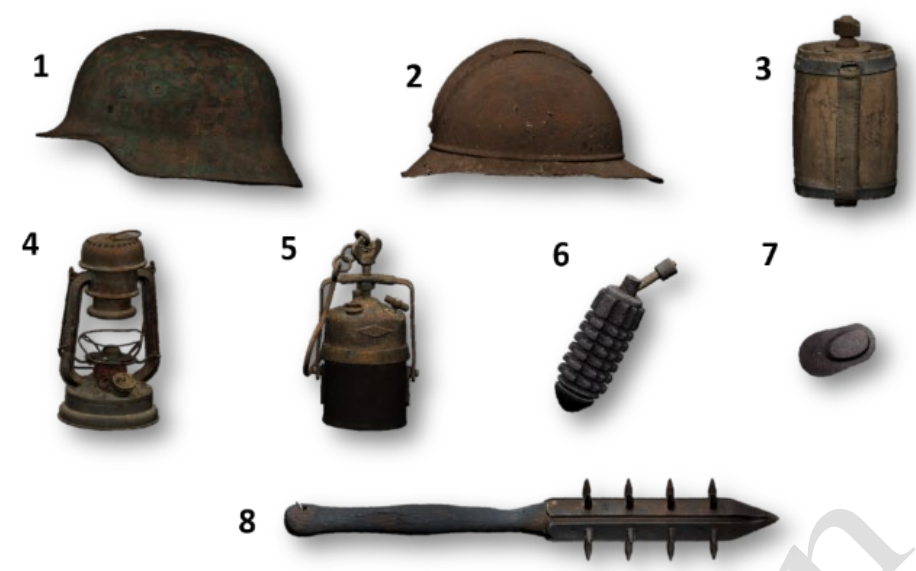

Fig. 8. (a) Scanning an Italian WWI helmet with 3D fringe project scanner. (b) Produced 3D models of war findings: 1) Austro-Hungarian helmet, 2) Italian helmet, 3) Water bottle, 4) Ditmar lamp, 5) Osmeka DB lamp, 6) Hand grenade, 7) Reinforced glasses, 8) Spiked club. All models are freely accessible on the web in the Europeana (http://www.europeana.eu/portal/en) and FBK-3DOM (http://3dom.fbk.eu/repository/portal/portal.html) portals.

\subsubsection{Sharing $3 D$ models on the web}

The realised 3D models of both forts and war findings have been shared online on the Europeana portal (http://www.europeana.eu/portal/en) and on the FBK3DOM 3D models repository (http://3dom.fbk.eu/repository/portal/portal.html). Each model is interactively visible in a javascript-base web viewer (https://code.google.com/archive/p/jsc3d/), embedded in a dedicated web page (Fig. 9), where all the relevant information (metadata, description of the surveying and modelling technique) are shown. 3D models can be obtained upon request. 


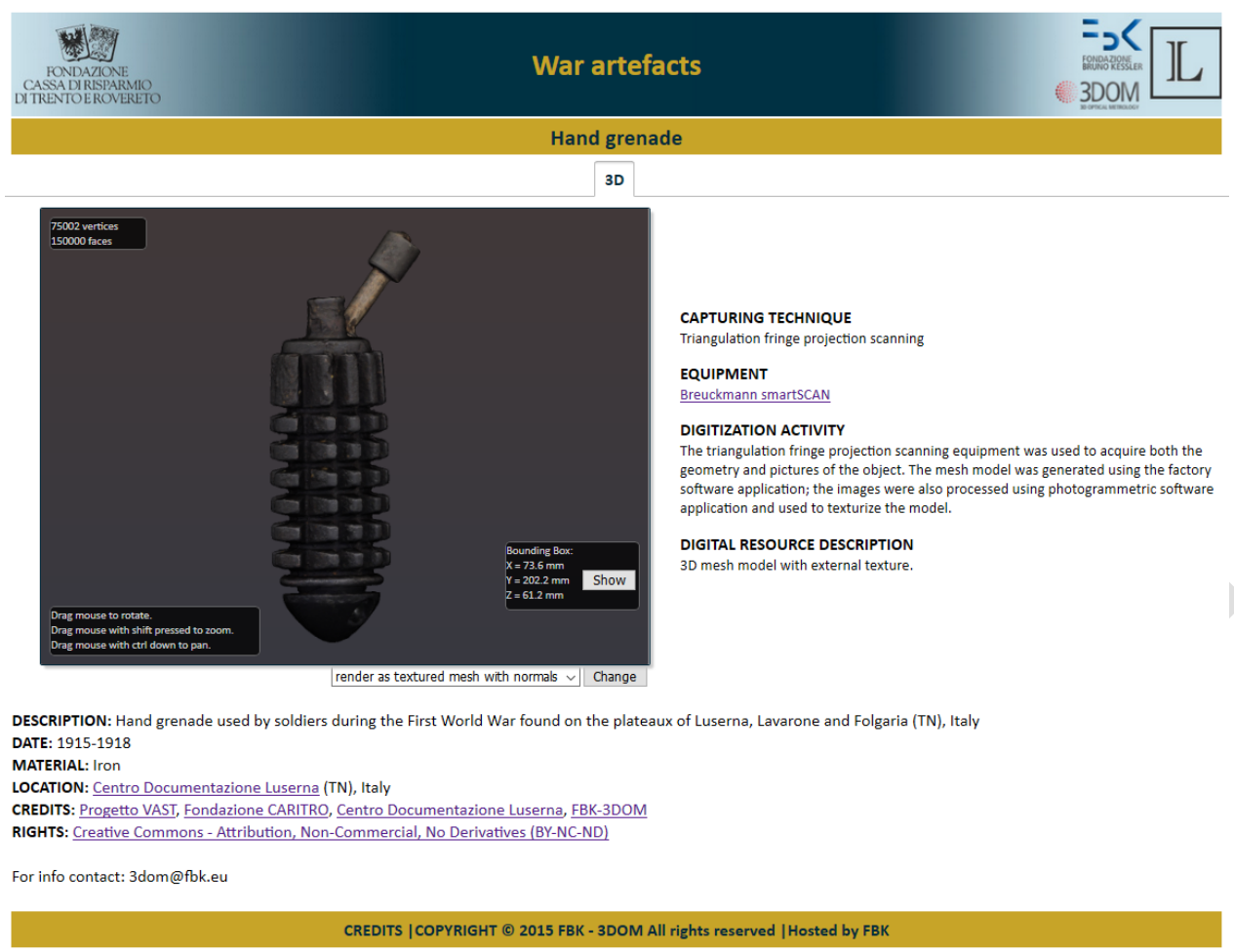

Fig. 9. Example of web page displaying the 3D model of a war finding.

\subsection{Virtual tour of war scenarios}

With the same goal of enhancing and valorizing the cultural value of war scenarios by increasing their visibility and consciousness, a virtual tour was realized (http://3dom.fbk.eu/repository/files/vast/vt/tour.html). It consists of panoramic images showing the war structures and present day situations (Fig. 10) and it is now on show in the local museum.

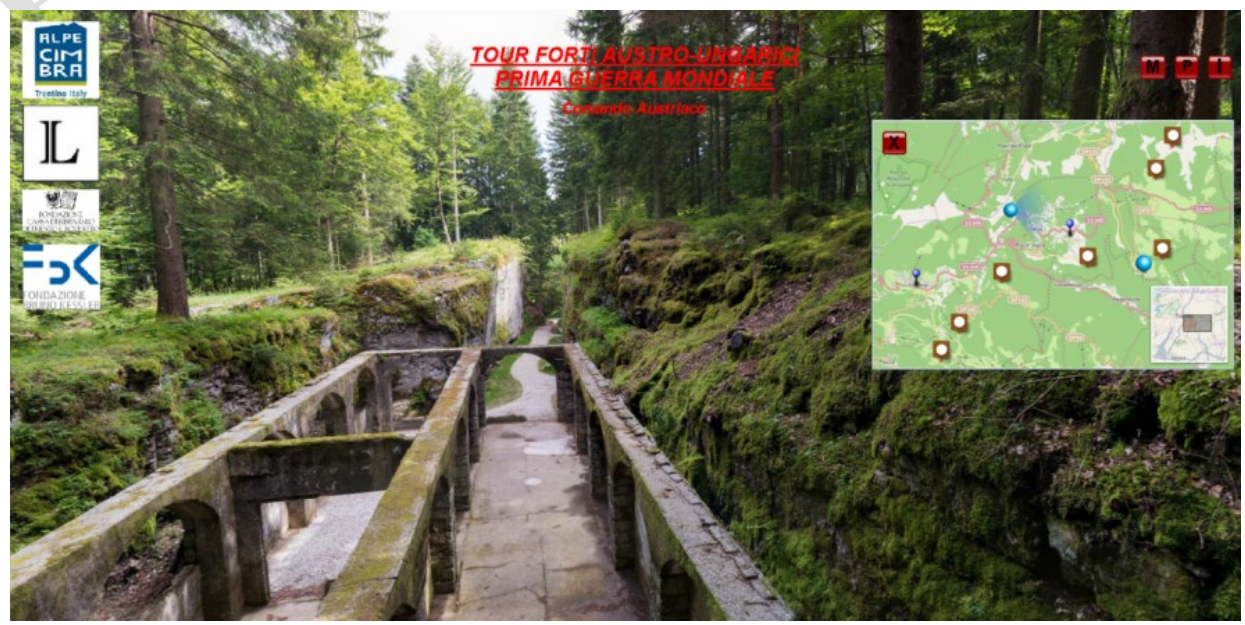


Fig. 10. The VAST virtual tour: a panoramic image of the Virti military structure.

\subsection{WebGIS}

In order to make publicly available all collected and heterogeneous (in type and provenance) data, a geographic information system (GIS) accessible online (WebGIS, http://vast-gis.fbk.eu) was realized (so far only in Italian language). On top of the actual cartographic information, layers of data can be displayed and queried. The web interface allows the user to view historical information, interrogate the project database and visualize specific data. The data included in the WebGIS were adapted for animating through projection a scale model of the landscape in a local museum (Fig. 11).
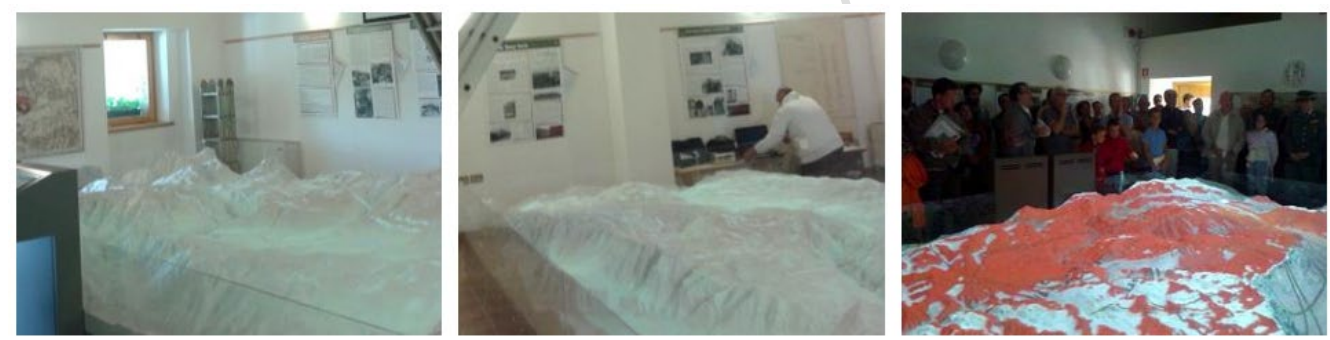

Fig. 11. 3D printed scaled model of the war landscape around Trento with cartographic layers projected on it.

\section{Follow-up of the project}

The expertise gained within the presented activities and the interest raised by the various outcomes led to various follow-up projects hereafter described.

\subsection{The Trento city fortress project}

The 'Trento Citta' Fortezza' (Trento City Fortress, http://trentocittafortezza.fbk.eu) project, realized in cooperation with a high school (Istituto Buonarroti-Pozzo, http://www.buonarroti.tn.it) in Trento, aimed to actively involve students in the creation of cartographic and multimedia products 
related to the city of Trento during the WWI. The city, being the largest and southern city of the Austro-Hungarian Empire, was fortified and heavily protected at the beginning of 1900 to defend its territory from any possible Italian military assault. The main objectives of the projects were to:

- collect heterogeneous data regarding the Fortress of Trento;

- $\quad$ survey and model some Austro-Hungarian military structures in the area of Trento, such as the fortifications on Monte Celva (Fig. 12a, http://3dom.fbk.eu/repository/3Dpointclouds/celva/index.html);

- realize end-products such as paper maps, WebGIS (Fig. 12b, http://3dom.fbk.eu/repository/files/ITT/gistcf.html) and Apps for mobile devices.

The WebGIS contains historic and tourist information, as well as visibility and artillery range analyses for the military structures included in the fortification system around Trento (http://3dom.fbk.eu/repository/files/ITT/gitevis.html).

a)



b)
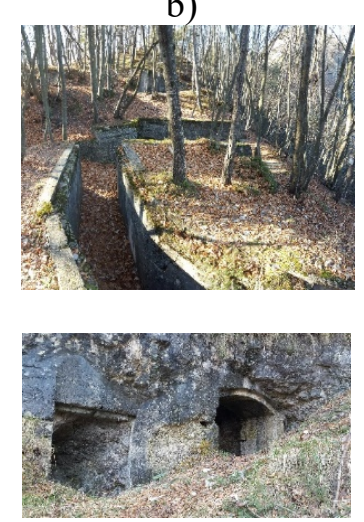

d)

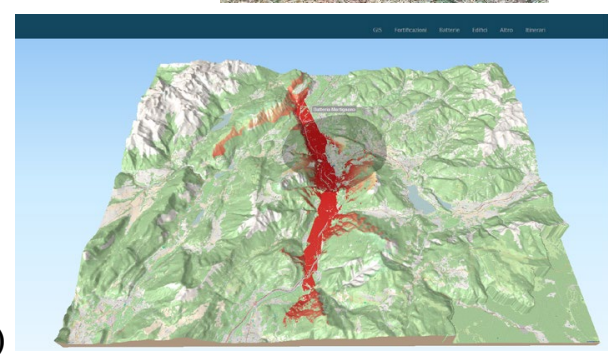

c)

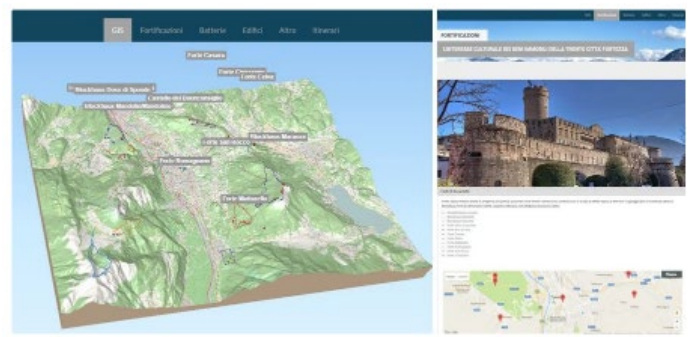

Fig. 12. (a) The Austro-Hungarian fortifications and underground tunnels on Mount Celva (Trento, Italy) and the realized communicative web portal with the surveying results (b) Typical WWI trenches and caves in the mountains. (c) The WebGIS of the 'Trento Citta' 
Fortezza' project with (d) its visibility analyses results (in red) and bombs' range (in grey) for one of the fort close to Trento.

\subsection{D surveying of Sommo Alto fort}

The internal and external 3D surveying of the Sommo Alto fort, located in Folgaria (Trento), was requested to plan its restoration and preservation works. The municipality of Folgaria needed detailed and up-to-date sections and plans of the military building for planning the rebuilding of its internal structures. Stating the challenging condition of the environment, characterised by narrow passages, debris, steep stairs, etc., a hand-held mobile indoor 3D mapping system (http://geoslam.com) was chosen for the survey. Portable mobile mapping systems (MMSs), either mounted on a robotic platform [17] or adapted to be easily carried or worn by persons $[18,19]$, are very efficient and convenient for fast 3D mapping in complex and indoor scenarios. Their potential accuracy was investigated in previous research papers, both in indoor [20-22] and outdoor scenarios [22, 23].

$2 \mathrm{D}$ drawings at 1:50 scale were extracted from a very dense point cloud of the fortification (Fig. 13); the final segmented 3D point cloud is accessible on-line (http://3dom.fbk.eu/repository/3Dpointclouds/index.html\#fortesommoalto).

a)



b)

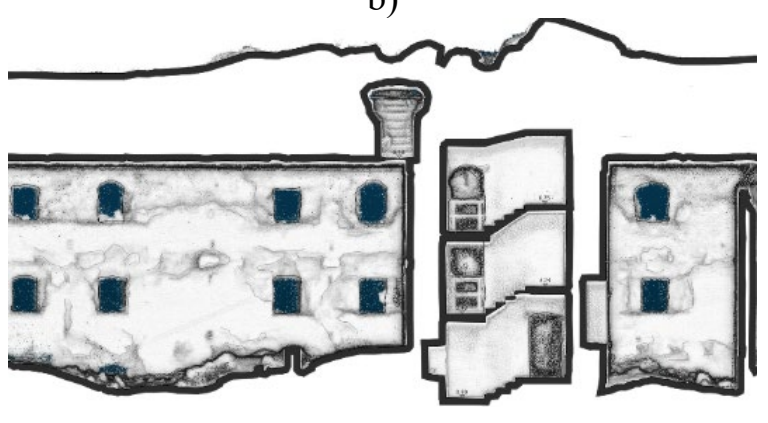

c)

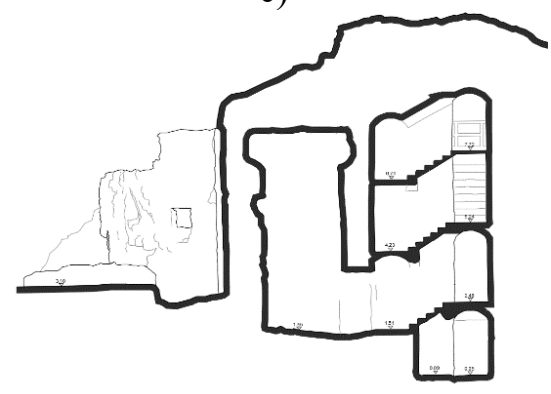


Fig. 13. (a) The point cloud of Sommo Alto fort. Examples of derived 2D drawings (scale 1:50) with (b) and without (c) the underlying point cloud section.

As the hand-held scanner provides only geometry information (3D points) without colour components, an in-house method to map color information onto the 3D data was developed. Two synchronized GoPro cameras, attached to the scan head (Fig. 14a), acquired two sequences of images which were afterwards processed with a photogrammetric workflow. The obtained RGB dense point cloud is then used to transfer the colour information to the ZEB point cloud (Fig. 14b-c).

a)

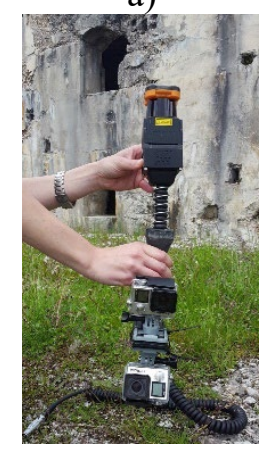

b)

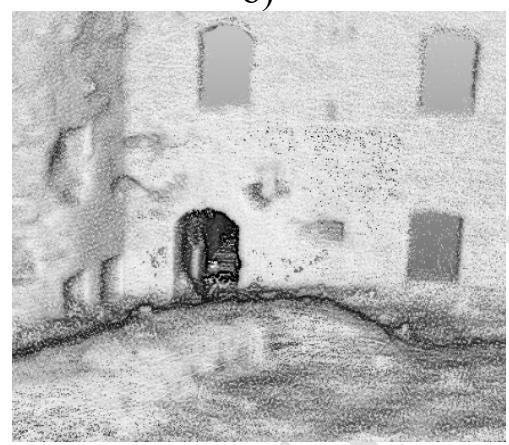

c)

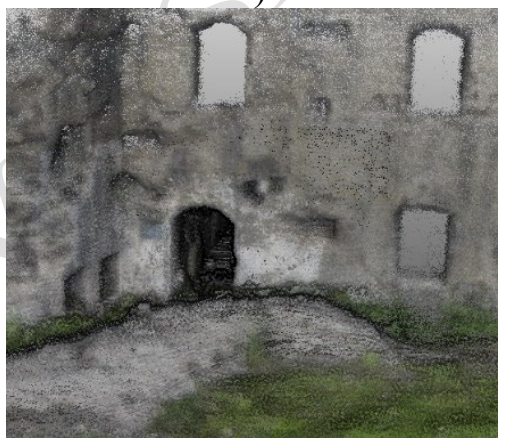

Fig. 14. The GoPro cameras fixed on the GeoSLAM ZEB1 device (a). The original (b) and colored (c) 3D point clouds.

\section{Discussion and conclusions}

The article reported the activities of the VAST project which has provided a timeless rebirth to the memory of WWI in the area of Trento. Reality-based 3D digital models of military structures were realized, based on historic evidences (drawings, maps and photos) and onsite measurements. Analogously, military objects found on the plateaus and now stored in the museums were digitized. All 3D models are now available on the web to allow access also with smart devices directly on site. Immersive virtual tours, communication material and WebGIS were 
also realized. The first, based on panoramic images, allow to travel and visit war scenarios ('warscape'), understand connections among forts in a virtual and unique way. Communication material, based on 3D reconstructed scenarios and objects, allow to disseminate cultural information and reach also young generations. The WebGIS displays the main war events and localizations such as fortification and trenches, positions, in order to enrich the geography of the territory with historic memory. The project outcomes are of great importance to valorise heritage scenarios which are slowly disappearing due to time (more than 100 years old), location (remote plateaus away from the main touristic areas), lack of conservation (war heritage is usually considered not of primary interest for conservation policies) and lack of interest (modern history is often regarded as of secondary importance in schools' educational programmes).

The WWI places and items have been enriched and empowered with new meaning thanks to the exploitation of 3D digital technologies. The possibility to access 3D digital models almost everywhere, even on trekking paths, allows also non-experts to understand better and deeper the history and culture of the territory. And this is even truer when it comes to the Austro-Hungarian forts now in ruins. Thanks to the VAST project, young generations can now 'see' and, hopefully, really understand what these complex and impressive structures should have been. Scientists and researchers can verify their own hypothesis and theories, make comparisons with buildings or war objects of other historic periods or present in other geographic and cultural areas. The results of the VAST project are expected to promote touristic and cultural richness of Cimbri area, mainly through their online (web) and onsite material. The 3D digital models may be included in farther 
products, like augmented or virtual reality (AR/VR) applications or serious games for education and awareness-raising.

\section{Acknowledgments}

The VAST project was partially funded by Fondazione Cassa di Risparmio di Trento e Rovereto - CARITRO. The authors are really thankful to all partners (Centro Documentazione Luserna, Istituto Cimbro Luserna, Centro Internazionale Studi di Archeologia di Superficie, Fondazione Forte Belvedere) involved in the VAST project, as well as Archivio Storico di Trento and the Azienda per il Turismo Folgaria, Lavarone e Luserna for their fundamental contribution and valuable support in the bibliographic and historical research.

Many thanks to students and professors of the Istituto Buonarroti-Pozzo in Trento for their cooperation in the Trento Citta' Fortezza project (http://trentocittafortezza.fbk.eu/home). The authors are also grateful to: (i) Dr. Nadia Guardini (Me.s.a. srl, http://www.mesa-laserscanner3d.com/) for providing the ZEB1 used for the survey of Sommo Alto; (ii) Dr. Dirk Rieke-Zapp (AICON 3D Systems GmbH, http://aicon3d.com/start.html) for providing the SmartScan AICON scanner employed for the digitization of war findings; (iii) SAL engineering (http://www.salengineering.it/public/en/1/index.asp) for their support with the UAV acquisition of Verle and Cherle forts.

\section{References}

[1] Coluzzi, P., 2004. Symbolic acquisition planning? The case of Cimbrian in Italy.

III Mercator Symposium 2004: "Linguistic diversity and education: 
challenges

and

opportunities".

http://www.cimbri.org/download/coluzzi2004.pdf.

[2] Cacciaguerra, G., Gatti, M. P., 2010. The modernity exhibited by the building technologies adopted for nineteenth century Trentino fortresses. Proc. IAHS World Congress on Housing 2010, Santander, pp. 1-9.

[3] Georgopoulos, A., 2014. 3D virtual reconstruction of archaeological monuments. Mediterranean Archaeology and Archaeometry, 14(4), pp.155164.

[4] Kinji, O., Andaroodi, E., Einifar, A. and Matini, M., 2008.3DCG reconstitution and virtual reality of UNESCO world heritage in danger. The Citadel Of Bam. Progress In Informatic, pp 99-136.

[5] Guidi, G., Russo, M., Ercoli, S., Remondino, F., Rizzi, A. and Menna, F., 2009. A multi-resolution methodology for the 3D modeling of large and complex archaeological areas. Int. Journal of Architectural Computing, 7(1), pp.39-55.

[6] Remondino, F., Gruen, A., von Schwerin, J., Eisenbeiss, H., Rizzi, A., Sauerbier, M. and Richards-Rissetto, H., 2009, October. Multi-sensor 3D documentation of the Maya site of Copan. In Proceedings of 22nd CIPA Symposium, Kyoto, Japan.

[7] Torres-Martínez, J.A., Seddaiu, M., Rodríguez-Gonzálvez, P., HernándezLópez, D. and González-Aguilera, D., 2015. A Multi-Data Source and MultiSensor Approach for the 3d Reconstruction and Visualization of a Complex Archaelogical Site: the Case Study of Tolmo de Minateda. Remote Sensing, 8(7), 550, pp. 1-25.

[8] Guidi, G., Russo, M. and Angheleddu, D., 2013. Digital Reconstruction of an Archaeological Site Based on the Integration of 3d Data and Historical 
Sources. ISPRS-International Archives of the Photogrammetry, Remote Sensing and Spatial Information Sciences, 1(1), pp.99-105.

[9] Hanke, K., Moser, M. and Rampold, R., 2015. Historic photos and TLS data fusion for the $3 \mathrm{D}$ reconstruction of a monastery altar ensemble. The International Archives of Photogrammetry, Remote Sensing and Spatial Information Sciences, 40(5), p.201.

[10] Rodríguez-Gonzálvez, P., Muñoz-Nieto, A. L., del Pozo, S., SanchezAparicio, L. J., Gonzalez-Aguilera, D., Micoli, L., Gonizzi Barsanti, S., Guidi, G., Mills, J., Fieber, K., Haynes, I., Hejmanowska, B., 2017. 4D reconstruction and visualization of cultural heritage: analysing our legacy through time. The International Archives of Photogrammetry, Remote Sensing and Spatial Information Sciences, XLII-2/W3, p.609-616

[11] Vincent, M. L., Coughenour, C., Remondino, F., Flores Gutierrez, M., LopezMenchero Bendicho, V. M., Frtisch, D., 2015: Crowd-sourcing the 3D digital reconstructions of lost cultural heritage. Digital Heritage 2015, Vol. 1, pp. 171-172, doi: 10.1109/DigitalHeritage.2015.7413863.

[12] Lindsay. K., 2013. World War I Centenary: Continuations and Beginnings. Final Report. Academic IT Services, University of Oxford. http://repository.jisc.ac.uk/5121/1/WW1C-FinalReport.pdf.

[13] Nocerino, E., Fiorillo, F., Minto, S., Menna, F. and Remondino, F., 2014. A non-conventional procedure for the 3D modeling of WWI forts. The International Archives of Photogrammetry, Remote Sensing and Spatial Information Sciences, Vol. XL-5, pp. 457-464.

[14] Rodríguez-Gonzálvez, P., Nocerino, E., Menna, F., Minto, S. and Remondino, F., 2015. 3D surveying \& modeling of underground passages in WWI 
fortifications. The International Archives of Photogrammetry, Remote Sensing and Spatial Information Sciences, Vol. XL-5/W4, pp. 17-24.

[15] Kazhdan, M. and Hoppe, H., 2013. Screened Poisson surface reconstruction. ACM Transactions on Graphics (TOG), 32(3), p.29.

[16] Garland, M. and Heckbert, P.S., 1997. Surface simplification using quadric error metrics. In Proceedings of the 24th annual conference on Computer graphics and interactive techniques. ACM Press/Addison-Wesley Publishing Co, pp. 209-216.

[17] Ziparo, V.A., Zaratti, M., Grisetti, G., Bonanni, T.M., Serafin, J., Di Cicco, M., Proesmans, M., Van Gool, L., Vysotska, O., Bogoslavskyi, I. and Stachniss, C., 2013, October. Exploration and mapping of catacombs with mobile robots. In Safety, Security, and Rescue Robotics (SSRR), 2013 IEEE International Symposium on (pp. 1-2). IEEE. [18] Zlot, R. and Bosse, M., 2014. Three-dimensional mobile mapping of caves. Journal of Cave and Karst Studies, 76(3), p.191.

[19] Farella, E.M, 2016.3D Mapping of underground environments with a handheld laser scanner. Proc. SIFET annual conference, Lecce, Italy.

[20] Glennie, C., Brooks, B., Ericksen, T., Hauser, D., Hudnut, K., Foster, J. and Avery, J., 2013. Compact multipurpose mobile laser scanning system-Initial tests and results. Remote Sensing, 5(2), pp.521-538.

[21] Rönnholm, P., Liang, X., Kukko, A., Jaakkola, A. and Hyyppä, J., 2016. Quality analysis and correction of mobile backpack laser scanning data. ISPRS Annals of Photogrammetry, Remote Sensing \& Spatial Information Sciences, 3(1). 
[22] Nocerino, E., Menna, F., Remondino, F., Toschi, I. and Rodríguez-Gonzálvez, P., 2017. Investigation of indoor and outdoor performance of two portable mobile mapping systems. In SPIE Optical Metrology (pp. 103320I-103320I). International Society for Optics and Photonics.

[23] Lauterbach, H.A., Borrmann, D., Heß, R., Eck, D., Schilling, K. and Nüchter, A., 2015. Evaluation of a backpack-mounted 3D mobile scanning system. Remote Sensing, 7(10), pp.13753-13781. 